\title{
MAIZE PRODUCTION EMULATION SYSTEM BASED ON COOPERATIVE MODELS
}

\author{
Shijuan $\mathrm{Li}^{1}$, Yeping Zhu ${ }^{1, *}$ \\ ${ }^{I}$ Agricultural Information Institute, Chinese Academy of Agricultural Sciences, Beijing, \\ China, 100081 \\ Corresponding author, Address: Library 311, Agricultural Information Institute, Chinese \\ Academy of Agricultural Sciences, No. 12 Zhongguancun South Street, Beijing, 100081, P. R. \\ China, Tel: +86-10-68919652-2342, Fax: +86-10-68919886-2339, Email: zhuyp@mail.caas.net.cn
}

Abstract: $\quad$ Based on the maize_ecophysiological characteristics, the maize developping process-based cooperative models including growth model,_developmental phase models, water balance model and nitrogen balance model etc. was built combined with the basic data such as variety characteristics, weather data, soil level and cultivation management with the technology support of system engineering method, crop simulation and computer. On the basis of cooperative models, this paper further constructed Maize Production Emulation System (MPES) with several additional functions such as determining variety characteristic parameters, deciding the planting design, simulating maize phenology stages and production features, warning of the nitrogen leaching in advance, simulating the water and nitrogen deficit degree and maize growth three-dimensional display. The system reproduces the maize production process in digital form. MPES was test through actual experiment, and the results verified its strong mechanism and prediction performance as well as its universal adaptation.

Keywords: maize; cooperative models; simulation; emulation system

\section{INTRODUCTION}

Beginning in 1960s, crop simulation model had been developed from infantility to maturation, from experiential form to mechanism explanation, from theory model to practical application. As the core of modern

Li, S. and Zhu, Y., 2008, in IFIP International Federation for Information Processing, Volume 259; Computer and Computing Technologies in Agriculture, Vol. 2; Daoliang Li; (Boston: Springer), pp. 1213-1221. 
agricultural production management and agricultural resource optimizing management, it is the foundation of precision agriculture and information agriculture implemented now in china. In America, Holand, England and Australia, It has been developed different advanced crop simulation system, respectively. Among them DSSAT developed by American contains many famous crop model, such as CERES, GROPGRO etc; APSIM developed by Australian integrates deferent models into a public platform, and can simulate crop, vegetable and weed production systems; SUCROS developed by Dutch comprises the practical models, MACROS, BACROS and WOFOST. Furthermore, the EPIC can be used to study effects of the climate change on agriculture. Though these models have been developed into powerful system, only the minority of them were applied to agricultural production successfully. At present, the basic role of crop simulation model is to predict yield, and it is also applied to research on world food supplies, ecology agriculture, regional yield prediction, soil resource management, effect evaluation on agriculture of environment and social economic etc.

With the development of information technology and the increase of social requirement, many countries have diversified their crop growth model, for example adding new technology (GIS, GPS, RS) or other models to improve its generality, veracity and operation. InfoCrop model evolved from several models could simulate the effects of weather, soils, agronomic management and major pests on crop growth, yield, soil carbon, nitrogen and water, and greenhouse gas emissions (Aggarwal et al., 2005). The Dynamic North Florida Dairy Farm Model (DyNoFlo) incorporated livestock model, manure $\mathrm{N}$ mode and crop model (Cabrera et al., 2006). The old edition for ORYZA were integrated to one rice model ORYZA2000, which simulates the growth and development of rice under conditions of potential production and water and nitrogen limitations (Bouman et al., 2006). A crop-parasitic weed interactions model was designed and implemented under the framework of the Agricultural Production Systems Simulator (APSIM), and became the first module to reflect biology treat in APSIM (Grenz et al., 2006). At the same time, many concerned researches appeared in China. Nanjing agricultural university developed WebGISbased system for agricultural spatial information management and assistant decision-making, which combined knowledge model with GIS and realized the functions as cropping system evaluation, ecological distribution of farm products, estimation of cropping potential production etc (Liu Xiaojun et al., 2006). According to the studies on WebGIS and ES, National Engineering Research Center for Information Technology in Agriculture constructed Crop Management Geography Information System including database, model library and repository (Li Xiang et al., 2003). 
On the basis of past researches (Yan Dingchun, 2005) and the deep analysis on maize growth and development discipline, the author applied system engineering, computer technology and model method to design maize cooperative models and built Maize Production Emulation System (MPES). It realizes the digital management for maize production, and will establish foundation for digital agriculture-based agricultural informatization.

\section{SYSTEM DESIGN AND STRUCTURE}

\subsection{Development environment and system design}

Using programming language Visual $\mathrm{C}++$ and Visual Basic 6.0 to design system interface, MPES was developed on the operation system of Windows 2000 server. Database was built in Access 2000, and forms and graphs output was carried out by Teechart control unit. The models had been integrated according to COM standard by programming language Visual $\mathrm{C}++$.

Cooperative models groupwares compose the main content and central work of the MPES, and the groupwares include maize growth model, development model, water balance model, $\mathrm{N}$ balance model, maize quality model, economic analysis model and pest forecast model, furthermore, it include variety parameter test module and weather creation module. Basic parameters database saves variety information, soil data and agronomic management. Weather data day by day are kept in weather database. The simulation and predicting results of models were transported into result database. Interface functions implement the data transfer between models and databases.

\subsection{System structure}

Based on the past studies, we collected related literatures and agronomic expert information in a large scale, then designed maize cooperative models in accordance with maize growth and development discipline, and combined the models with corresponding database and repository, and constitute Maize Production Emulation System (MPES). The system consists of cooperative models, database and interface etc. Next its components will be elaborated.

Following figure 1 shows the detail system structure. 


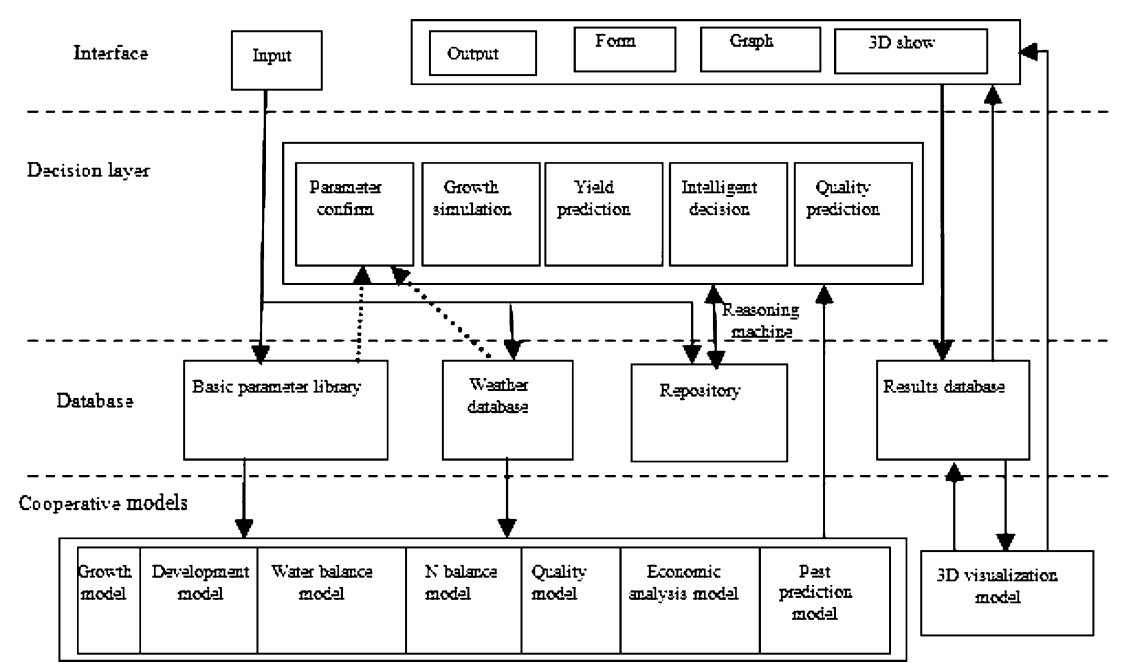

Figure 1. The system structure for maize production emulation system

\subsubsection{Databases}

Including basic parameter database, weather database, repository and results database.

Basic parameter database consists of the information about location, fertilizer type, fertilizer management, irrigation management, cultivation variety, phenology data, soil texture and soil parameter, among which phenology data, as actual experiment data, was used to determine the genetic characteristic parameters for certain variety; soil parameters contain former crop remains information, water content before sowing, and organic matter percent, volume weight, $\mathrm{NH}_{4}-\mathrm{N}, \mathrm{NO}_{3}-\mathrm{N}$ and $\mathrm{PH}$ of every soil layer.

The datum of daily highest temperature, lowest temperature, rain and solar radiation or sunlight time input by user are saved in weather database. The qualitatively technology knowledge about maize cultivation can not be analyzed quantitatively through models. Thereby, they are expressed with production rule and concluded into repository, which solves the practical problems by means of reasoning machine according to the input and aim of users. Results database stores the simulation results from cooperative models and decision layer, and the tables are set on the basis of the output menus.

\subsubsection{Cooperative models}

Based on the past modeling experiences, agronomic knowledge and experimental data, deep analysis on maize growth and development 
discipline, and applying system engineering, computer technology and model method, we quantified maize growth and its effective factors to several models which realized valid cooperation. The following gives details of the main cooperative models, respectively.

\section{(1) Maize growth model}

It computes LAI, Light Interception, photosynthesis, and dry matter production and distribution in maize, and calculates $\mathrm{N}$ uptake and distribution, described by $\mathrm{N}$ content and percent for plant and every organ. Firstly, daily potential accumulation of dry matter is estimated according to photosynthesis effective radiation. Secondly, considered the effects of temperature, water and $\mathrm{N}$ on photosynthesis, Daily actual accumulation of dry matter is calculated. In every development stage, maize plants has different growth center and distribution rule of dry matter. For example, at grain filling stage, photosynthate was allocated priority to grain, which is the growth center. If intraday photosynthesis matter is not enough for grain intraday increase, all the newly photosynthate was transported to grain, and temporary dry matter stored in stem was reallocated to grain to meet the demand of grain growth.

\section{(2) Maize development model}

This model divided maize development into 8 stages: from sowing to germination, from germination to seeding emergence, from seeding emergence to juvenile stage, from juvenile stage to jointing stage, from jointing stage to silking stage, from silking stage to beginning of grain filling, from beginning of grain filling to physiological maturity. Temperature, water, photoperiod and genetic parameter restrict the replacement of development stages. Genetic parameter can be input by user or decided automatically by parameter determination program in system.

\section{(3) Water balance model}

Based on water movement rules, soil water status and maize absorption characteristic, Water balance model simulates field potential and actual evapotranspiration. The model considered soil from surface to two meters depth, and divided it into 10 layers. Based on weather data and basic parameter input by user, after counting the soil water restricting parameters, model calculates water leakage, runoff, soil evaporation, plant transpiration and root water absorption. Priestly-Taylor equation and SCS Curve Number Method are adopted to simulate potential evapotranspiration and runoff, respectively. Water deficit index calculated by this model affects directly daily accumulated value of maize dry matter and increases amount in LAI. Model contains a water-saving module which offers irrigation management on the basis of irrigation target set by user. 


\section{(4) $\mathrm{N}$ balance model}

This model mainly simulates the processes of $\mathrm{N}$ mineralization and fixation, $\mathrm{N}$ losses and uptake by maize. Corresponding with the soil layers in water balance model, it counts and renews $\mathrm{N}$ content of every layer in terms of the water movement up and down, and the $\mathrm{N}$ deficit index calculated by the model affects directly daily accumulated value of maize dry matter and LAI. Firstly, the mineralization amount of organic matter in soil is calculated, and $\mathrm{N}\left(\mathrm{NH}_{4}-\mathrm{N}\right.$ and $\left.\mathrm{NO}_{3}-\mathrm{N}\right)$ released from fertilizer should be added at the data of fertilized. Secondly, model computes nitrification and denitrification, $\mathrm{N}$ deficit index, $\mathrm{N}$ uptake amount by maize plant and organs (leaf, stem, ear and grain). Finally the amount of nitrate leached to the second meters depth soil layer with water movement is counted, and evaluated possible effects of the leached nitrate on groundwater.

\section{(5) Grain quality model}

Combining past research achievement or results and the relative literatures collected in a large scale, we analyzed the effects on main maize quality (protein, starch and fat) of variety trait, weather, cultivation management and nutrition, and got the algorithm with Logistic equation to draw up the relation between quality and factors such as density, days after grain-filling, water and nutrition, then built maize quality model, which integrated with maize growth model very well.

\section{(6) Economic analysis model}

This model offers optimal variety, sowing date and density when user choose a target variety such as variety with highest yield, largest ratio of output to input, highest net income and lowest input. It can calculate annual total input, output and net income to offer decision-making support for user in terms of the relative input.

\section{(7) Pest prediction model}

With the increasing study on crop simulation model, more and more researcher attach importance to pest prediction. Some information system may be used to pest investigation and prediction in America and Europe. Holland and Germany developed special wheat plant protection decisionmaking system EPIPRE and PRO-PLANT (Forrer, H.R. et al, 1992; Frahm, J. et al, 1993). MPES considered the major maize pest-maize borer, and use nerve network prediction method to built model. After study training according to effect factors set by user, and integrating weather data and plant density, the model can simulate the occurrence law of maize borer. 


\section{(8) 3D visualization model}

3D visualization model mainly simulates the maize growth based on agronomic shape knowledge, image and 3D animation technology, and the simulation data in results database. It makes it easy to observe and predict maize growth, development and yield formation directly. The methods such as rigid body kinematics and flexible system were applied to model construction in order to realize the functions such as zoom, growing longer, growth, horizontal movement, rotation, color change and total shape change.

\subsubsection{Decision layer}

Applying the above maize cooperative models and repository, decision layer implements maize growth simulation, yield and yield components prediction, maize quality prediction and intelligent decision-making. In addition, genetic parameter determination module creates the characteristics needed by maize development model automatically on the basis of basic parameter database and weather data.

\subsubsection{System interface}

User operates system or models on the interface, which includes data input and results output. System has friendly and beautiful interface, and it's easy to be operated and understood. The parameter input unit reduced the amount of parameters that is uneasy to get for user. Simulation results are showed with form and graph, and system can show the daily data of more than 40 indexes. 3D visualization show simulates the shape changes of seed, root, stem, leaf, spike and female flowers from sowing to maturity, and the corresponding content for soil water, NO3-N and NH4-N are displayed on the right screen. Fig. 2 is one picture for 3D maize visualization show.

\section{FUNCTIONS OF MPES AND DEMONSTRATION ANALYSIS}

MPES simulates maize production of different varieties under different location and yield levels with one day as time step. System has the following functions: 1) It simulates yield and yield components, main quality formation, dynamic change of soil water and $\mathrm{N}$, water and $\mathrm{N}$ uptake and utilization by maize, $\mathrm{N}$ leaching, and shows the simulation results with form and chart directly. 2) It gives anticipative target yield and quality, variety 
choose, sowing date and density determination, fertilizer and water management according to user's requirement and biological environment of decision location. Based on simulation model, system analyzes maize variety, water and nutrition status, weather resource and offers assistant decisionmaking, such as the suggestions on optimal variety, sowing date and density, the amount and time of irrigation and fertilizer. 3) Maize 3D visualization shows maize growth vividly, and it is the real reflect of simulation results from cooperative models.

Using actual experiment data under deferent water conditions in 1996 and 1997 in Hebei province, we calibrated and validated Maize Production Emulation System based on cooperative models. Results indicated the system has good prediction performance and strong applicability. The RMES of yield and biomass predicted by system were $426.3 \mathrm{~kg} / \mathrm{hm}-2,477.5$ $\mathrm{kg} / \mathrm{hm}-2$ and $1029.8 \mathrm{~kg} / \mathrm{hm}-2,1356.0 \mathrm{~kg} / \mathrm{hm}-2$ respectively. The relative RMES were $6.78 \%, 5.55 \%$ and $7.60 \%, 7.50 \%$, all less than $10 \%$. Fig. 3 and Fig. 4 show the correlation between prediction value and observation value for yield and biomass.



Figure 2. Maize 3D visualization show

\section{ACKNOWLEDGEMENTS}

This research was supported by Digital Agriculture Program of State Hightech Research and Development Project of China (No. 20060110Z2059), and by National Scientific and Technical Supporting Programs Funded by Ministry of Science and Technology of China (2006BAD10A06). 


\section{REFERENCES}

Aggarwal, P.K., et al. InfoCrop: a dynamic simulation model for theassessment of crop yields, losses due to pests, and environmental impact of agro-ecosystems in tropicalenvironments. I. Model description. Agr. Syst. 2005

Bouman, B.A.M., et al. Description and evaluation of the rice growth model ORYZA2000 under nitrogen-limited conditions, Agricultural Systems, 2006, 87: 249-273

Forrer, H.R., Experiences with the cereal disease forecast system EPIPRE in Switzerland and prospects for the use of diagnostics to monitor the disease state. Brighton Crop Protection Conference, Pests and Diseases, 1992, (2): 711-720

Frahm, J., et al. PRO_PLANT - a computer-based decision-support system for cereal disease control. Bulletin-OEPP. 1993, 23(4): 685-69

Grenz, J.H., et al. Simulating crop-parasitic weed interactions using APSIM: Model evaluation and application, Europ. J. Agronomy 2006, 24: 257-267

Li Xiang, et al. Study on the Crop M anagement Inform ation System Based on W ebGIS and ES, Acta Agriculturae Boreali-Sinica, 2003, 18(2): 106-109 (in Chinese)

Liu Xiaojun, et al. WebGIS-based system for agricultural spatial information management and aided decision-making, Transactions of the Chinese Society of Agricultural Engineering, 2006, 22(5): 125-129 (in Chinese)

Victor, E., et al. An integrated North Florida dairy farm model to reduce environmental impacts under seasonal climate variability, Agriculture, Ecosystems and Environment, 2006, 113: 82-97

Yan Dingchun, et al. A Knowledge Model- and Growth Model-based Management System For Corn. Proceeding of the Third International Symposium on Intelligent Information Technology in Agriculture (ISIITA), 2005, pp. 14-16, Beijing, China. 